\title{
$\mathrm{CO}_{2}$ 레이저 침구 치료의 역사
}

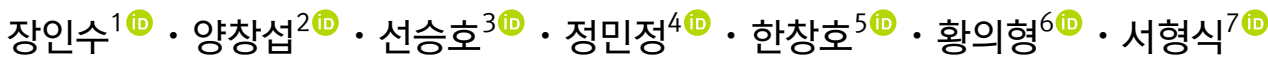 \\ ${ }^{1}$ 우석대학교 한의과대학 한방내과학교실, ${ }^{2}$ 한국한의학연구원, ${ }^{3}$ 상지대학교 한의과대학 한방내과학교실, ${ }^{4}$ 우석대학교 한의과대학 한방소아과학교실, \\ 동국대학교 한의과대학 한방내과학교실, ${ }^{6}$ 부산대학교 한의학전문대학원 한방재활의학교실, \\ 부산대학교 한의학전문대학원 한방안이비인후피부과학교실
}

\section{The History of $\mathrm{CO}_{2}$ Laser Acupuncture and Moxibustion}

\author{
Insoo Jang ${ }^{1}$, Changsop Yang ${ }^{2}$, Seungho Sun ${ }^{3}$, Minjeong Jeong ${ }^{4}$ \\ Changho Han ${ }^{5}$, Eui-Hyoung Hwang ${ }^{6}$, Hyungsik Seo
}

\begin{abstract}
${ }^{1}$ Department of Internal Medicine, College of Korean Medicine, Woosuk University, ${ }^{2}$ Korea Institute of Oriental Medicine, ${ }^{3}$ Department of Internal Medicine, College of Korean Medicine, Sangji University, ${ }^{4}$ Department of Pediatrics, College of Korean Medicine, Woosuk University, ${ }^{5}$ Department of Internal Medicine, College of Korean Medicine, Dong-guk University, ${ }^{6}$ Department of Rehabilitation Medicine, School of Korean Medicine, Pusan National University, ${ }^{7}$ Department of Ophthalmology, Otolaryngology and Dermatology, School of Korean Medicine, Pusan National University
\end{abstract}

Objectives : Carbon dioxide $\left(\mathrm{CO}_{2}\right)$ laser, a high power laser has been used for pain management, dermatology, and surgery and laser acupuncture and moxibustion as well, since it had been oscillated in 1964 at Bell Telephone Laboratories in the US. The purpose of this study is to investigate the history of $\mathrm{CO}_{2}$ laser acupuncture through reviewing studies published in early stage of laser medicine. Methods : To investigate the early history of $\mathrm{CO}_{2}$ laser acupuncture, studies were searched in the electronic databases, including PubMed, ScienceDirect, CNKI, Wanfang, J-STAGE, CiNii, KTNP, and OASIS, since 1964. Articles in English, Chinese, Japanese and Korean were included, and there were no limitations in literature types such as reviews, essays, clinical trials, animal experiments and veterinary research. Results : We found that the first $\mathrm{CO}_{2}$ laser application to acupoints was done by a research team in Shanghai in 1976. They used $\mathrm{CO}_{2}$ laser for acupuncture treatment and it was also the first laser acupuncture treatment in China. Since the first case report of $\mathrm{CO}_{2}$ laser for leukopenia, it has been applied to various diseases in China, Korea, Japan and other western countries. It has been widely applied in the fields of dentistry and veterinary medicine, as well as clinical applications. Conclusions: Not only $\mathrm{CO}_{2}$ laser can be used as laser acupuncture by stimulating the acupoints and meridians, but also can produce moxibustion effect by using heat stimulus. Therefore, it is expected that it will be used in various clinical fields in the future.

Key words : laser acupuncture, carbon dioxide laser, $\mathrm{CO}_{2}$, Korean Medicine

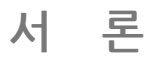

레이저는 짧은 역사에 비해서 다양한 산업 분야에서 널리 사용 되고 있다 ${ }^{1,2)}$. 1960년에 Maiman에 의해서 세계 최초의 레이저인
루비레이저가 처음 개발되었으며, 1961년에 $\mathrm{HeNe}$ 레이저가, 1964년에 이산화탄소(carbon dioxide: $\mathrm{CO}_{2}$ ) 레이저가 만들어졌 고, 이후 다양한 매질의 레이저가 등장하였다 ${ }^{1,2)}$. 레이저는 1962년 부터 의료의 영역에서 쓰이기 시작해서 지난 60 년 동안 의학의 역

Received March 11, 2019, Revised March 14, 2019, Accepted March 17, 2019

Corresponding author: Minjeong Jeong

Department of Pediatrics, College of Korean Medicine, Woosuk University Hospital, Eoeun-ro 46, Jeonbuk 54987, Korea

Tel: +82-63-220-8608, Fax: +82-63-220-8616, E-mail: vocation0313@gmail.com

This study was supported by the Korea Health Industry Development Institute (KHIDI) (HI16C0322).

(C) This is an open access article distributed under the terms of the Creative Commons Attribution Non-Commercial License (http://creativecommons.org/licenses/ by-nc/4.0) which permits unrestricted non-commercial use, distribution, and reproduction in any medium, provided the original work is properly cited. 
사에 커다란 발전을 가져왔다 ${ }^{1-3}$. 한의 임상에서는 1973 년에 캐나 다의 Plog에 의해서 레이저를 귀의 경혈을 자극하기 위한 목적으로 사용하기 시작한 이래로 레이저침이 다양하게 활용되고 있고 많은 연구가 보고되고 있다 ${ }^{1-5)}$.

저자들은 이전의 연구를 통해서 레이저의 특성에 따른 레이저 침의 활용 장비들에 대해서 고찰하고 ${ }^{6}$, 고출력 레이저(high power laser)의 한의 임상 활용에 대한 연구를 살펴본 바 있닥. 현재 한의 임상에서는 저단계 레이저(low level laser)는 물론이고, $\mathrm{CO}_{2}$, YAG 레이저 등 다양한 매질의 고출력 레이저가 레이저 침구 시술 에 활용되고 있다. 최근 저단계 레이저도 점차 높은 출력의 장비가 활용되는 추세이며), 슈퍼펄싱(super pulsing) 기술이 발전하면서, $10 \mathrm{~W}$ 이상의 대단히 높은 출력을 가지면서도 밀리초(millisecond) 이하의 조사 시간을 가지는 High intensity laser therapy (HILT) 도 보편화되고 있다. 따라서 고출력 레이저를 이용한 침구 치료는 앞으로도 더 넓은 범위에서 활용될 것으로 기대되고 있다.

그러나 다양한 활용에도 불구하고, $\mathrm{CO}_{2}$ 레이저가 언제부터 침구 치료에 사용되기 시작했는지에 대한 연구보고는 없었다. 이에 고출 력 레이저 중에서 활용 범위가 넓고 오랜 역사를 가지고 있는 $\mathrm{CO}_{2}$ 레이저의 한의 임상 활용에 대한 역사 및 향후 발전 방향에 대해서 고찰해보고자 한다.

\section{본 론}

$\mathrm{CO}_{2}$ 레이저의 침구학 임상 활용에 대한 역사를 고찰하기 위하여 $\mathrm{CO}_{2}$ 레이저가 처음으로 개발된 1964년 이후부터 최근까지 나온 문헌을 조사하였다. 문헌 조사를 위하여 PubMed, Science Direct, CNKI, Wanfang database, J-STAGE, CiNii, 전통지식포털(KTNP, www.koreantk.com), OASIS (oasis.kiom.re.kr) 등의 검색 엔진 을 이용하여 검색하였다. 검색어로는 'laser acupuncture', 'Carbon dioxide laser', ' $\mathrm{CO}_{2}$ laser', “二氧化碳 激光”, ' $\mathrm{CO}_{2}$ 激光”, ‘レー ザー鍼 “炭酸ガスレーザー鍼, ‘이산화탄소 레이저', ' $\mathrm{CO}_{2}$ 레이 저' 등을 선택하여 조사하였으며, 문헌의 형식은 특별한 제한을 두 지 않았다. 임상 연구는 물론, 동물실험도 포괄하여 $\mathrm{CO}_{2}$ 레이저를 경혈에 조사하여 침 뜸에 활용한 문헌을 모두 조사하였으며, 기본 적인 검색어를 토대로 검색한 후에 관련된 문헌을 확인하고 연구에 포함시켰다. 이를 토대로 임상에서의 $\mathrm{CO}_{2}$ 레이저침뜸의 활용을 살 펴보았다.

\section{1. 레이저침의 기원과 $\mathrm{CO}_{2}$ 레이저침}

1960년대에 레이저가 개발되고 외과 수술을 비롯한 의학적 용 도로 사용하기 시작하였다. 그리고 얼마 지나지 않아 전통의학의 영역에서도 활용 범위가 넓어지게 되었다. 레이저침을 최초로 사용 한 시례는 독일계 캐나다 의사인 Plog가 1973년경부터 사용한 것 으로 알려져 있다). Plog는 1980년에 발표한 논문에서 1973년부 터 레이저침 시술에 사용했던 정확한 레이저 기기 기종과 구체적인 시술 방법을 자세하게 밝혀놓았고 ${ }^{5}$, 시술 사진을 포함한 상세한 기 술이 되어 있기 때문에 학계에서는 Plog를 최초로 보는데 이견이 없다 ${ }^{1)}$

그러나 러시아에서 약간 앞선 시기인 1970년대 초에 경혈에 레 이저침을 조사하는 반사요법(reflexology)에 사용되었다는 문헌들 이 있다.89. Utemuratova와 Sokolova (1970)는 HeNe 레이저를 이용하여 경혈 조사를 통해 고혈압 치료를 시도하였으며, Ermukhambetov는 1971년에 $12 \mathrm{~mW}$ 의 HeNe 레이저를 이용하 여 경혈 조사를 통해 고혈압을 치료하였고, Shchur (1972)는 20 $\mathrm{mW}$ 의 $\mathrm{HeNe}$ 레이저침을 이용해서 고혈압 환자를 치료하였다. Voronina (1972)와 Voronina and Inyushin (1972)은 HeNe 레이 저를 경혈에 조사하여 bronchial asthma를 치료하였다고 보고하 기도 하였다. 이들 문헌은 대부분 학술대회 보고(proceeding) 형태 이긴 하지만, 적응증이나 치료방법에 대한 기술이 서술되어 있기 때문에 간과할 수 없다고 판단된다. 따라서 레이저침의 기원에 대 해서는 추가적인 학회의 논의가 필요할 것으로 생각된다 ${ }^{8,9)}$.

앞서 언급한 대로 $\mathrm{CO}_{2}$ 레이저는 1964년에 처음 개발되었으며, 초기에는 주로 외과적인 수술 목적으로 많이 시술되었다. 그러던 중 고출력 에너지로 인한 열자극 효과를 응용하여 1970년대 중반 부터 continuous mode 또는 defocusing mode에서 경혈에 직접 적인 자극을 가하는 용도로 널리 활용되었다. $\mathrm{CO}_{2}$ 레이저의 특성 상 물리적인 자극은 물론 강한 온열자극을 줄 수 있기 때문에, 직접 구(直接炎)와 동일한 원리를 사용하므로 여러 문헌들에서 '레이저 침(laser acupuncture)'과 '레이저뜸(laser moxibustion)'이라는 용어가 함께 사용되고 있다 ${ }^{10,11}$.

\section{2. 중국에서의 $\mathrm{CO}_{2}$ 레이저침뜸}

중국 문헌에서는 $\mathrm{CO}_{2}$ 레이저를 '二氧化碳激光'이라고 표현하 며, 1976년에 상하이의 상해해원의원(上海海员医院)에서 처음 사 용한 것으로 보고되고 있다 ${ }^{12}$. 이 연구는 $\mathrm{CO}_{2}$ 레이저 침구치료 분 야의 최초 연구인 것으로 생각되며, 28세의 백혈구감소증(leukopenia) 환자를 대상으로 $\mathrm{CO}_{2}$ 레이저를 $50 \mathrm{~W}$, continuous mode 에서 SP10 (血海), SP6 (三陰交)에 조사하여 호전시킨 증례를 보고 
하였다 ${ }^{12)}$. 같은 병원에서 1976년에 보도된 또 다른 연구에서는 $\mathrm{CO}_{2}$ 레이저를 이용하여 경혈에 조사하는 치료법에 대한 소개와 자체 제작한 $\mathrm{CO}_{2}$ 레이저 조사기의 작동 원리에 대해서 자세히 소 개하였다 ${ }^{13)}$.

激光医用研究协作组에서 1977년에 보도한 한 논문에서 레이저 치료와 변증(辨登)을 언급하고 있다 ${ }^{14}$. 이 보고에서 $\mathrm{CO}_{2}$ 레이저를 defocusing 할 경우 구법(负法)과 동일하며, 온보작용(溫補作用)이 있다고 설명하였다. 저자들은 만성위염에는 상복부에 조사하며, 한 증(寒症)의 견관절주위염에 효과적이라고 보고하였으며, 구(炎) 치 료(治療)를 시행할 병증에는 $\mathrm{CO}_{2}$ 레이저를 defocusing 해서 사용 한다고 하였다. 또한 백혈구감소증은 혈허증(血虛登)의 관점에서 혈해(SP10), 삼음교(SP6)에 $\mathrm{CO}_{2}$ 레이저를 사용한다고 하였으며, 풍한증(風寒登)의 급성 비염은 코 주위에 레이저를 조사하면, 신온 해표(辛溫解表)의 치료 원칙에 부합된다고 언급하였다 ${ }^{14)}$.

王传文(1978)은 西安醫學院에서 盆腔炎(Pelvic inflammatory disease)에 환부 및 주위 경혈에 $\mathrm{CO}_{2}$ 레이저를 조사해서 치료한 증례를 소개하였다 ${ }^{15)}$.

朱健 등(1979)은 $\mathrm{CO}_{2}$ 레이저를 이용한 정형외과 적응증을 대상 으로 하는 치료 증례에서 견관절주위염, 연골염, 염좌, 인대손상, 족근통, 건초염을 비롯한 다양한 질환에 대해서 통처(痛處) 및 아시 혈(阿是穴)에 조사하여 치료하였다 ${ }^{16}$.

柳文治 등(1979)은 탈모증에 $\mathrm{CO}_{2}$ 레이저를 조사하여 치료한 증 례를 소개하였으며, 경혈 자극으로 인한 전신적인 개선 효과에 대 해서 부가적으로 설명하였닥.

叶廷珖(1979)은 氦氖激光(HeNe), 器激光(Argon), 氪離子激光 (Krypton) 레이저 및 二氧化碳激光 $\left(\mathrm{CO}_{2}\right)$, 鐿鋁石榴石激光( $\left.\mathrm{YAG}\right)$ 레이저의 각각의 특성과 침구치료에서의 활용을 정리하였다 ${ }^{18}$. 그 는 $\mathrm{CO}_{2}$ 레이저의 경우 광구(光炎)로서 활용되며, 온열 효과는 물론 환부를 소작시킬 수 있다고 설명하였다. 뜸치료에서도 소작구(燒次 소), 화농구(化膿炎)와 같이 직접 피부의 조직에 강한 열자극을 가 하는 구법(솟ㅊㅊ)에 $\mathrm{CO}_{2}$ 레이저를 적용하기도 한다고 하였다. 본 연 구에서는 외과, 내과, 피부과, 안과, 이비인후과 등을 망라하는 다양 한 질환에 레이저 침구치료를 소개하였다.

金锡萶 등(1979)은 수의학 분야에서 최초로 $\mathrm{CO}_{2}$ 레이저를 활용 한 레이저침을 소개하였는데, 돼지의 교소혈(交巢穴)에 $\mathrm{CO}_{2}$ 레이 저를 사용하여 자극을 가해서 새끼돼지의 이질을 치료하는 연구를 보고하였다. 그는 종전에는 화침(火鍼)을 사용했으나, 1978년부터 화침(火鍼)을 대신하여 $\mathrm{CO}_{2}$ 레이저를 활용한 연구를 진행하였으며 효과가 우수하였다고 하였다 ${ }^{19)}$. 그는 또 다른 2 편의 연구(1980)에 서 각각 다른 증례들을 소개하였다 ${ }^{20,211}$.
任华轶(1980)는 $\mathrm{CO}_{2}, \mathrm{NeCd}, \mathrm{N}_{2}$, Argon, Krypton, HeNe 레이 저를 비롯한 다양한 매질이 레이저침으로 활용된다고 하였다 22 . 陈昌钧(1980)은 수의학 영역에서의 침 마취를 연구하였으며, $\mathrm{CO}_{2}$ 레이저침을 이용하여 수술전 유도마취를 실시하였다 ${ }^{23}$. 그는 실험동물로 사용된 황소, 물소, 염소를 대상으로 각각 인중(人中), 백회혈(百會穴), 협척혈(夾猆穴)에 대하여 레이저 자극을 가하여 레 이저침 마취에 성공하였다. 또다른 연구에서 그는(1980) 레이저침 의 마취 및 진통효과를 관찰하기 위하여, 황소, 물소, 염소를 대상으 로 협척혈(夾脊穴)에 대한 레이저침 마취와 창풍(搶風), 삼양락혈 (三陽絡穴)에 대한 전침 마취 그리고 morphine 마취 등의 효과를 비교한 동물실험을 진행하여 우수한 효과를 보고하였다마.

张伟(1982) 등은 한 동물실험 연구에서 건강한 돼지의 백회혈 (百會穴)과 토끼의 이곽(耳殼)에 $\mathrm{CO}_{2}$ 레이저침을 조사하고 혈액 검 사를 실시하여 면역기능에 미치는 영향을 확인하였다 ${ }^{25)}$.

蒋次柏(1982) 등은 한 연구에서 10마리의 건강한 말을 대상으 로 $30 \mathrm{~W}$ 의 출력에서 관원수(關元兪) 양혈(兩穴)에 $\mathrm{CO}_{2}$ 레이저 뜸을 시술하였다. 그는 레이저 시술후 혈액검사를 실시하여 면역기 능을 측정한 결과를 보고하였다 ${ }^{26}$.

周岳城(1980, 1984)은 레이저침 시술로 유럽에 널리 알려져 있 는 연구자로, 치의학 분야에서 1979 1980년 동안 $\mathrm{HeNe}$ 레이저 침을 이용한 레이저침 마취를 시술하였다 ${ }^{27,28)}$. 그는 1982년부터는 $\mathrm{CO}_{2}$ 레이저침 마취를 활용하여 발치 및 구강안면부의 수술을 시행 하였으며(1983), 합곡(LI4), 사백(ST2), 관료(SI18), 협거(ST6) 혈을 사용하여 마취 수술을 수행한 333례의 증례를 보고하였다 ${ }^{29}$. 周岳 城(1987)은 이후 또다른 연구에서 $\mathrm{CO}_{2}$ 레이저침 마취와 $\mathrm{HeNe}$ 레 이저침 마취를 활용하여 치의학 영역에서 침 마취를 시술하고 각각 의 출력 변화에 따른 마취 효과를 비교한 연구를 보고하였다일.

周自动(1984) 등은 수의학 영역에서 다양한 질환에 활용되고 있는 $\mathrm{HeNe}$ 레이저와 $\mathrm{CO}_{2}$ 레이저침구 치료를 정리하여 보고하였다 ${ }^{31}$.

李树滋 (1984)는 $\mathrm{CO}_{2}$ 레이저침을 이용한 치료를 적응증 별로 정 리하였으며, 수의외과 분야에서의 $\mathrm{CO}_{2}$ 마취를 비롯하여 四川農學 院 家畜銊刺麻醉小組의 1980년 연구성과 등을 소개하였고, 수의내 과, 전염병과 등에 대한 $\mathrm{CO}_{2}$ 레이저의 경혈조사 치료 적응증도 정 리하였다 32 .

王绍维(1985)는 말科(Equidae) 동물의 소화기 급증 질환인 결 증(結店) (gastrointestinal obstruction)에 대해서 $\mathrm{CO}_{2}$ 레이저침을 이용하여 경혈을 소작(燒枃)하는 치료를 보고하였다. 결증(結症)은 음식물이 장관내에서 막혀서 소화불량, 변비 등을 일으키는 증상을 말하며, 주로 분변이 장관 내에서 폐색되어 이동이 불가능한 증상 으로서 출구폐쇄형 변비(outlet obstruction)를 지칭한다. 그는 말 
과 노새에서 발생한 장결증(晹結症)에 대해서 비수(脾俞), 관원수 (關元俞), 대장수(大腸俞), 기해수(氣海俞), 통장(通腸) 등의 경혈에 $\mathrm{CO}_{2}$ 레이저를 이용하여 경혈을 소작(燒火勺)하여 치료한 결과 실험 조에서 $87.32 \%$ 가 효과를 보였다고 보고하였다 ${ }^{33)}$.

于船(1985)은 $\mathrm{CO}_{2}$ 레이저와 $\mathrm{HeNe}$ 레이저를 실험동물(토끼, 양) 의 백회혈(百會穴)에 조사한 다음 혈중 5-HT를 조사하여 레이저침 의 진통작용 기전에 대하여 실험적으로 확인하였다 ${ }^{34)}$.

孙长美(1985)는 염소를 대상으로 $\mathrm{CO}_{2}$ 레이저를 비수(脾俞), 관 원혈(關元穴)에 조사한 다음 혈액검사를 실시하여 결과를 분석하고 혈액 조성 성분에 미치는 영향과 소염 작용, 면역 기능에 미치는 영향 등을 조사하여 보고하였다 35 .

蔡少阁(1980)은 40마리의 토끼를 대상으로 실험군과 대조군으 로 무작위배정하여 $\mathrm{CO}_{2}$ 레이저를 교소혈(交巢穴)에 조사하였다. 실험 결과 레이저 조사군에서 대조군에 비하여 면역혈청의 뚜렷한 변화가 관찰되었다 ${ }^{36}$.

陶冾(1987)는 말, 노새의 소화기 급증 질환인 결증(結店)에 대해 서 $\mathrm{CO}_{2}$ 레이저침을 활용한 경혈 소작(燒枃) 치료 결과를 보고하였 다. 그는 직장경을 통해서 결증으로 확진된 말 28 마리와 노새 2 마 리를 대상으로 $30 \mathrm{~W}$ 의 $\mathrm{CO}_{2}$ 레이저침을 활용하여 좌우의 비수(脾 俞), 관원혈(關元穴)과 대장수(大腸俞), 통장(通腸), 기해혈(氣海穴) 에 대해서 각 경혈마다 6초씩 경혈 소작술을 시행하였다. 그는 치료 결과 레이저침을 이용한 경혈 소작술이 높은 치료 효과를 보였다고 보고하였다 ${ }^{37)}$.

张克家(1988)는 수의학 영역에서의 레이저치료의 고찰을 통해 서 $\mathrm{CO}_{2}$ 레이저침을 활용한 다양한 임상 수의학 증례 및 치료 원리 를 소개하였다 ${ }^{38)}$. 특히 수의학 분야에서는 다른 레이저침과 함께 $\mathrm{CO}_{2}$ 레이저침을 활용하는 시례가 높으며, 열 자극 및 전신적인 치 료에 대한 효과가 높은 편이다 ${ }^{38)}$.

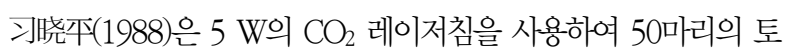
끼를 실험군과 대조군으로 나누고 교소혈(交巢穴)과 후삼리혈(後三 里穴에 자극을 가하고 나서 면역세포와 $\operatorname{IgG}$ 를 비롯한 면역항체에 미치는 영향을 조사하였다. 그 결과 면역 항체의 증가와 T세포l, 호중구의 증가 등이 관찰되었다고 보고하였다 ${ }^{39)}$.

何扬子(1988)는 기관지천식 환자 32례를 대상으로 $\mathrm{CO}_{2}$ 레이저 침 치료군과 뜸치료군으로 나누고 천돌(CV22), 폐수(BL13), 전중 (CV17), 정천(定喘, EX-B1) 혈에 대해서 각각 치료를 시행하였다. 그 결과 기존에 치료효과가 확인된 뜸 치료군은 물론 $\mathrm{CO}_{2}$ 레이저 침 치료군에서도 양호한 치료 효과를 얻었다고 보고하였다 ${ }^{40)}$.

刘云(1993)은 수의학 영역에서의 레이저 치료를 고찰하면서 $\mathrm{CO}_{2}$ 레이저침이 레이저침마취에 널리 활용되고 있다고 보고하였
다 ${ }^{411}$.

何扬子(1994)는 허한증(虛寒裋)으로 변증(辨登)된 96례의 기관 지천식 환자를 대상으로 $\mathrm{CO}_{2}$ 레이저침 치료군과 뜸치료군으로 나 누어 경혈에 시술 후 증상의 변화와 최대호기량( $\mathrm{PEF})$ 을 평가하여 비교하였다 ${ }^{42}$. 사용한 경혈은 천돌(CV22), 폐수(BL13), 전중(CV17), 정천(定喘, $\mathrm{EX}-\mathrm{B} 1$ ) 혈이었으며, 치료 결과 $\mathrm{CO}_{2}$ 레이저치료군에서 치료 효과가 더 우수하였다. 그는 또다른 연구(1995, 1996)에서 역시 기관지천식 환자를 대상으로 임상 결과를 보고하였으며, 기전 규명을 위한 RCT 연구 결과도 발표하였다 ${ }^{43,44)}$.

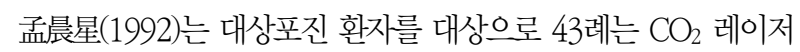
뜸 치료를 시행하였고, 39례른 애조구(艾條炎)를 사용한 뜸치료를 시행하여 비교한 결과, 진통작용과 대상포진후 상처에 딱지(crust) 가 생성되는 시간을 측정한 결과 $\mathrm{CO}_{2}$ 레이저뜸 치료군에서 더 좋 은 효과가 있었다고 보고하였다 ${ }^{45}$.

이상의 내용을 통해서 살펴볼 때, 중국에서는 오랫동안 $\mathrm{CO}_{2}$ 레 이저를 활용한 레이저침, 레이저뜸을 임상에서 활용해 왔으며, 다 양한 임상 적용증에 활용함은 물론 치의학 영역과 수의학 영역에서 도 $\mathrm{CO}_{2}$ 레이저를 활용한 레이저침뜸을 널리 활용해 왔음을 확인할 수 있다.

\section{3. 일본에서의 $\mathrm{CO}_{2}$ 레이저침뜸}

일본의 전통의학 임상에서도 레이저침(レーザー鍼)이 다양하게 활용되고 있으며, $\mathrm{HeNe}$ 레이저, YAG 레이저, GaAlAs 레이저 등을 비롯한 다양한 레이징 매질이 침치료 목적으로 활용되어 왔다 ${ }^{46,47)}$.

石川昌広(Masahiro Ishikawa) (1988)는 경혈자극 목적으로 시 술되는 레이저침을 사용할 때 피하조직 내에서 어떤 형태로 열자극 이 전파되는가를 관찰하기 위하여, $\mathrm{CO}_{2}$ 레이저침과 $\mathrm{YAG}$ 레이저침 의 열응력(thermal stress)을 측정하고 효과의 차이를 실험적으로 비교하였다 ${ }^{48)}$.

大浪洋二(Ohnami Yohji) (1996)는 수의학 분야에서 $\mathrm{CO}_{2}$ 레이 저의 효과를 관찰하기 위하여, 27마리의 Holstein 젖소를 대상으로 시험군 $(n=22)$ 과 무처치 대조군 $(n=5)$ 으로 나눈 뒤, 분만 직후부터 $2 \sim 3$ 일 이내에 2회에 걸쳐서 하루 걸러 $\mathrm{CO}_{2}$ 레이저를 교소혈(交巢 穴)에 $6 \mathrm{~W}$ 의 출력에서 60 초 동안 조사하였다. 조사 결과 악로(惡 露가 소실되는데 걸리는 기간은 실험군에서 21.3일, 대조군에서는 31.4 일로 조사되었으며 통계적으로 유의하였다 $(p<0.05)$. 또한 분 만 이후 자궁 완전회복에 이르기까지 걸리는 기간이 실험군에서는 23.3 일, 대조군에서는 32.8 일로 조사되었다 $(p<0.01)$. 연구자들은 $\mathrm{CO}_{2}$ 레이저 침이 분만 이후 자궁 회복에 긍정적인 영향을 끼쳤다 고 보고하였다 ${ }^{49)}$. 


\section{4. 국내에서의 $\mathrm{CO}_{2}$ 레이저침뜸}

국내 한의학 임상에서 레이저침은 1980년도 경부터 시술되기 시작한 것으로 보인다 ${ }^{50)}$. 레이저침 시술 초기에는 $\mathrm{HeNe}$ 레이저가 많이 사용되었다. $\mathrm{CO}_{2}$ 레이저침과 $\mathrm{YAG}$ 레이저침 또한 오랫동안 국내 한의학 임상에서 사용되어 왔다. 그러나, 자료가 충분하지 않 아서 정확히 언제부터 사용되었는지는 확인하기 어렵다.

고경석(1986)은 $\mathrm{CO}_{2}$ 레이저의 레이저침 활용 방법에 대한 제언 을 언급하였다 ${ }^{51}$.

이정민(1995)는 '한방침술(레이저침)을 이용한 가축 질병치료' 논문에서 수의학 분야에서 $\mathrm{CO}_{2}$ 레이저를 이용한 경혈 조사에 대해 소개하였다 ${ }^{52)}$.

김용남(1999) $)^{53)}$, 이휘준(2004) ${ }^{54)}$ 은 한의학 임상에서 $\mathrm{CO}_{2}$ 레이 저를 임상 각과에 활용한다고 하였다.

황의형 등(2009) $)^{6}$, 양창섭 등(2011 $)^{7)}$ 의 연구에서도 $\mathrm{CO}_{2}$ 레이저 침에 대해서 언급하고 있으며, 아울러 침구시술안전가이드(2011)2, 침구의학(2016) $)^{4)}$ 한방재활의학(2016) ${ }^{55)}$, 대학경락경혈학실습 $(2015)^{56)}$ 등에서는 $\mathrm{CO}_{2}$ 레이저침 치료를 자세하게 다루고 있다.

\section{5. 서구 및 기타 국가에서의 $\mathrm{CO}_{2}$ 레이저침뜸}

Chester 등(1991)의 'Laser Systems for Photobiology and Photomedicine'에 수록된 보고에 따르면 사슴의 Biyu 혈에 대한 $\mathrm{CO}_{2}$ 레이저 침 치료가 T-cell의 분화와 $\mathrm{WBC}$ 의 식세포작용을 촉진 하였다고 하였다 ${ }^{57}$.

Shen 등(2009) ${ }^{10)}$ 은 미국 메릴랜드대에서 수행된 연구에서 $\mathrm{CO}_{2}$ 레이저침과 InGaAlP 레이저를 활용하여 무릎골관절염에 대한 레 이저침뜸 치료의 효과를 확인하기 위한 임상시험을 진행한 결과를 보고하였다. 보고에 따르면 2005년부터 2006년까지 40명의 무릎 골관절염 환자를 무작위로 나누고 무릎에 있는 경혈에 $\mathrm{CO}_{2}$ 레이저 침과 가짜 레이저침을 각각 시술하였다. 연구결과 몇 가지 제한점 이 있음에도 불구하고, $\mathrm{CO}_{2}$ 레이저침뜸은 무릎골관절염에 효과가 있다고 보고하였다. 같은 연구팀이 발표한 다른 연구에서 Zhao 등 $(2010)^{11)}$ 은 레이저침뜸 치료가 안전하며, 2주간 치료가 무릎골관 절염에 효과가 있었다고 하였다.

Friedemann 등(2012)은 몇몇 경혈에 대한 $\mathrm{CO}_{2}$ 레이저 조사가 심혈관계 기능에 영향을 미친다는 동물실험 논문을 발표하였다 ${ }^{58)}$.

Zand (2012)는 통증성 구강질환에 대한 $\mathrm{CO}_{2}$ 레이저 치료를 설 명하면서, $\mathrm{CO}_{2}$ 레이저가 레이저침 분야에서 다양하게 쓰이고 있고, $\mathrm{HeNe}$ 레이저보다 더 효과가 우수하다는 임상 보고도 있다고 언급 하였다 59 .

Tunér and Hode (1999)는 레이저 치료에 대한 교과서에서
$\mathrm{CO}_{2}$ 레이저가 레이저침에 많이 쓰인다는 사실을 언급하였고, 진통 목적으로 시술할 때 $\mathrm{CO}_{2}$ 레이저의 조사량에 대해서도 기술하였다.

\section{고찰 및 결론}

저자들은 침구치료 분야에서 오랜 역사를 가진 $\mathrm{CO}_{2}$ 레이저를 사용한 레이저침뜸의 역사를 고찰하였다. 지금까지 살펴본 바와 같 이 $\mathrm{CO}_{2}$ 레이저는 레이저침이 처음으로 사용되기 시작한 시기로부 터 몇 년 지나지 않은 1976년부터 쓰이기 시작하여 다양한 임상 적용증에 대하여 쓰이면서 레이저침의 오랜 역사를 함께 하여왔다. 온열작용을 적극적으로 활용할 수 있다는 장점 때문에 레이저뜸이 라고 불리기도 하며, 한의 임상은 물론 수의침구학 분야에서도 널 리 활용되어 왔다.

$\mathrm{CO}_{2}$ 레이저는 고출력 레이저에 속하며, 높은 열을 낼 뿐만 아니 라 투과 깊이가 낮아서 조직의 표부와 얕은 부위를 자극하는데 효 과적이다. $\mathrm{CO}_{2}$ 레이저의 이러한 특성은 물에 대한 친화성이 높은 $\mathrm{CO}_{2}$ 레이저의 레이징매질(lasing medium)의 특성과 밀접한 관련 이 있다. 수분 함량이 높은 인체의 피부 및 피하 조직은 $\mathrm{CO}_{2}$ 레이저 와 만나게 되면 에너지의 대부분을 열에너지로 전환하여 소모되게 만들어 광선이 피하의 깊은 조직으로 투과하는 것을 차단하게 된 다. 이같은 특성은 피부에 존재하는 병변을 치료하거나 한의학의 경피(經皮)를 넓게 자극할 수도 있고, 피부 및 피하의 얕은 부위에 존재하는 경혈(經穴)을 자극하려는 목적에도 유용하다. 또한 레이 저의 광선 특성을 바꾸어 defocusing 하거나 fractional mode로 전환시켜서 넓은 부분을 자극하는 차침(車鍼) 또는 매화침(梅花鍼) 의 치료 목적으로 사용하는데 유용하다.

그리고, $\mathrm{CO}_{2}$ 레이저는 외과 분야에서 절단(cutting)과 응고 (coagulation), 기화(vaporization)와 같이 조직을 파괴하는 목적으 로 많이 사용되고 있지만, YAG 레이저와 함께 photobiomodulation 기능을 통하여 에너지를 생성하고 조직을 살리는 생화 기능 (生化機能)을 함께 가지고 있다. 이 같은 $\mathrm{CO}_{2}$ 레이저의 양면성은 한의 임상에서도 더욱 유용하게 쓰일 수 있는 기반이 된다.

아울러 point irradiation은 물론 defocusing mode, fractional mode를 이용하여 target tissue와 병변 특성에 맞춰서 다양하게 활용할 수 있는 장점이 있기 때문에 $\mathrm{CO}_{2}$ 레이저의 한의 임상 활용 은 매우 다양하다. 한의 임상에서 과거의 $\mathrm{CO}_{2}$ 레이저가 온열효과 를 위주로 하는 레이저뜸에 국한된 목적으로 많이 시술되었다면, 현재의 $\mathrm{CO}_{2}$ 레이저는 매화침레이저와 같은 fractional 기능을 구현 하여 넓은 면적을 다양한 형태로 자극하는 효과를 비롯하여 폭넓은 
목적으로 사용되고 있다. 따라서 향후 미래의 $\mathrm{CO}_{2}$ 레이저는 한의 임상에서 적응증을 확대하고 기술 개발과 질적 수준이 높은 임상 연구를 통하여 보편적으로 활용될 것으로 기대한다.

\section{감사의 글}

This study was supported by the Korea Health Industry Development Institute (KHIDI) (HI16C0322).

\section{References}

1. Tunér, Hode L. Laser Phototherapy, clinical practice and scientific background. Grangesberg, Sweden: Prima Books AB. $2014 ; 44-9 ; 90 ; 102 ; 119 ; 149$.

2. Ku S, Kim S, Park H, Shin S, Lee S, Jang I, et al. The safety guideline on the acupuncture treatment procedure. Seoul:Kunja publisher. 2011 ; 109-15.

3. Litscher G, Schikora D. Laser-needle acupuncture. Seoul: Medical Korea 2007; 28-9; 96; 100-111.

4. The textbook compilation committee of Korean acupuncture \& moxibustion society. Acupuncture medicine. Seoul: Jipmundang. $2017 ; 214,225-8$.

5. Plog FMW. Biophysical application of the laser beam. In: Koebner HK, editor. Lasers in medicine. New York : John Wiley $1980 ; 21-37$.

6. Hwang E, Yang C, Jang I. The Spectrum of Laser Instruments for Laser Acupuncture Application. The Journal of Korean Acupuncture \& Moxibustion Society. 2009; 26(1) : 49-57.

7. Yang C, Sun S, Jang I. High Intensity Laser for Laser Acupuncture Application. Korean Journal of Acupuncture. 2011 ; 28(3) : 1-12. doi: 10.1016/j.jams.2011.11.007.

8. Gamaleya NF. Laser biomedical research in the USSR. In: Laser applications in medicine and biology. Vol 3. Wolbarsht M.L. (ed.). New York: Plenum Publishing Corp. 1977:1-173. doi: 10.1007/978-1-4615-7326-5.

9. Shchur VV, Makeyeva NS, Belyayev VP, Starshinov GV. Arterial hypertension and neurological illnesses treated by helium-neon laser. American Journal of Acupuncture 1975 ; 3(2) : 165-6.
10. Shen X, Zhao L, Ding G, Tan M, Gao J, Wang L, et al. Effect of combined laser acupuncture on knee osteoarthritis: a pilot study. Lasers Med Sci. 2009 ; 24(2) : 129-36.

11. Zhao L, Shen X, Cheng K, Deng H, Ding G, Tan M, et al. Validating a nonacupoint sham control for laser treatment of knee osteoarthritis. Photomed Laser Surg 2010 ; 28(3) : 351-6. doi: 10.1089/pho.2009.2511.

12. Shanghai Seamen's hospital. Laser irradiation on the acupoints is helpful for the early stage of leukopenia. Laser. 1976;3(4) : 48.

13. Shanghai Seamen's hospital. The medical laser by self-manufacture. Medical Equipment 1976;2(5) : 41-7.

14. Medical laser research group. Medical laser and integrated traditional chinese and western medicine. Journal of medicine and pharmacy 1977 ; 4(1) : 9-12.

15. Wang C. Laser application in obstetrics and gynecology. Medical research communication. 1978; 7(3):30-5.

16. Zhu J, Liu W. The 100 case reports of surgical indications using carbon dioxide laser. Academic Journal of Guangzhou Medical College $1979 ; 7(1): 27-30$.

17. Liu W, Zhu J. CO2 laser irradiation on hair loss. Laser. 1979; 6(11) : 62-3

18. Xie T. Laser acupuncture moxibustion. Journal of Lanzhou Medical College 1979; 6(2): 170-3. [In Chinese]

19. Jin X, Zhu Q. A primary research of the carbon dioxide laser treatment on the swine dysentery. Sichuan Animal and Veterinary Sciences 1979; 6(3) : 50-3.

20. Jin $\mathrm{X}, \mathrm{Zhu} \mathrm{Q}$. Carbon dioxide laser treatment on the swine dysentery. Chinese Journal of Traditional Veterinary Science $1980 ; 8(2): 37-41$

21. Jin $\mathrm{X}$, Zhu Q. Carbon dioxide laser treatment on the swine dysentery. Sichuan Laser 1980 ; 3(1) : 24-7.

22. Ren H. Light acupuncture. Journal of Traditional Chinese Medicine 1980 ; 21(11) : 76-8.

23. Chen C, Wang C, Yang Y, Yang R, Zhao J, Liu C, Fu Y. Veterinary laser on the preoperative anesthesia. Chinese Veterinary Science $1980 ; 10(5): 1-5$.

24. Chen C, Wang C, Yang Y, Yang R, Zhao J, Liu C, et al. Measurement of pain threshold using Carbon dioxide laser in livestock. Sichuan Animal \& Veterinary Sciences 1980 ; 7(2) : 
$1-6$.

25. Zhang W, Wang S, Jiang X, Guo Y, Xu Q. The effect of carbon dioxide laser for acupuncture points on the immune function of experimental animals. Animal Husbandry and Veterinary Medicine $1982 ; 14(4): 154-5$.

26. Jiang C, Shi Z, Wang S. The investigation of burn stimulus quantity of equine points by carbon dioxide laser. Chinese Journal of Veterinary Science $1982 ; 2(4): 360-5$.

27. Zhou Y, Du M. Laser acupuncture anesthesia and clinical observation on 500 cases of surgical removal of teeth. Journal of Sichuan University (Medical Science Edition) 1980 ; (03) : 229-32. [In Chinese]

28. Zhou YC. An advanced clinical trial with laser acupuncture anesthesia for minor operations in the oro-maxillofacial region. Lasers Surg Med. 1984 ; 4(3) : 297-303. doi: 10.1002/lsm. 1900040311.

29. Zhou Y, Yin W. Clinical effects of CO2 laser acupuncture anesthesia. Sichuan Laser 1983 ; 4(3) : 170-3. doi: 10.14016/j.cnki.jgzz.1983.03.011.

30. Zhou Y. Clinical observation and comparison of anesthesia effect between $\mathrm{CO} 2$ and HeNe laser. Journal of Comprehensive Stomatology 1987 ; 3(1) : 14-7. doi: 10.13701/j.cnki.kqyxyj. 1987.01.009.

31. Chou Z. Laser application on animal husbandry and veterinary. Journal of Shihezi University (Natural Science) 1984 ; 2(2) : $83-8$.

32. Li S. Laser technique lecture (III). Heilongjiang Animal Science and Veterinary Medicine 1984 ; 8(5) : 42-6. doi: 10.13881/ j.cnki.hljxmsy.1984.05.026.

33. Wang S, Peng W, Chen S, Li Y, Qian S, Du H. Observation on the gastrointestinal obstruction in horses using $\mathrm{CO} 2$ laser cauterization on acupoints. Chinese Journal of Veterinary Science 1985 ; 5(2) : 9-11. doi: 10.16303/j.cnki.1005-4545.1985. 01.002.

34. Yu C. The influence of augmentation of brain 5-HT neuronal activity on laser acupoint stimulation analgesia. Chinese Journal of Pathophysiology 1985 ; 1(4) : 36-9. doi: 10.13702/j. 1000-0607.1985.03.011.

35. Sun C. The physiological effect of carbon dioxide laser irradiation on acupoints of goat. Veterinary Science in China. 1985;
15(8) ; 12-6. doi: 10.16656/j.issn.1673-4696.1985.08.004.

36. Cai S, Yu C. The immunoseroligic effect of carbon dioxide laser irradiation on acupoints of rabbits. Chinese Journal of Traditional Veterinary Science 1986 ; 14(3) : 5-6.

37. Tao Y. The effect of acupoints laser cauterization on the gastrointestinal obstruction in horses. Veterinary Science in China 1987 ; 17(3) : 45-6. doi: 10.16656/j.issn.1673-4696.1987.03. 025.

38. Chang K. laser acupuncture moxibustion in veterinary medicine. Chinese Journal of Veterinary Medicine 1988; 14(4) : 40-3.

39. Diao X, Yu C. The effects on the blood morphology and the immune function of rabbit after carbon dioxide laser irradiation on the acupoints. Chinese Journal of Veterinary Medicine 1988 ; 14(9) : 42-3

40. He Y, Liang Z. Treatment on bronchial asthma by CO2 laser points irradiation: a report of 32 cases. Journal of Optoelectronics Laser $1988 ; 7(4): 242-5$.

41. Liu Y, Li S. Application of laser in Chinese veterinary medicine and prodyction animal. Laser Biology 1993 ; 2(1) : 229-40.

42. He Y, Liang Z. Treatment of bronchial asthma with $\mathrm{CO} 2$ laser irradiation at points. Chinese acupuncture and moxibustion $1994 ; 14(1): 13-6$

43. He Y. The effect of $\mathrm{CO} 2$ laser moxibustion on pulmonary ventilation of asthmatic patients. Chinese acupuncture and moxibustion $1995 ; 15(3): 1-6$.

44. He Y. Exploration on Mechanism of Laser Moxibustion in the Treatment of Bronchial Asthma. Chinese acupuncture and moxibustion 1996 ; 16(12) : 7-9.

45. Meng C. Laser irradiation and moxibustion for the treatment of herpes zoster. Chinese acupuncture and moxibustion 1992 ; $12(6): 24-5$.

46. Kubo U. Medical Applications of Lasers. The Review of Laser Engineering 1983 ; 11(9) : 698-714.

47. Watsuji T, Ishimaru K, Shinohara S, Kitade T, Yukimachi T. Studies on the Effects of Low Energy Laser Irradiation Therapy. Kampo Medicine 1991 ; 42(2) : 259-64. doi: 10.3937/ kampomed.42.259.

48. Ishikawa M, Fujiwara O, Katoh K, Azakami T. Spatial Distribution of Thermal Stress inside Human Skin Tissue caused by Laser Acupuncture. The Review of Laser Engineering 1988 ; 16(7) : 
410-6. doi: 10.2184/lsj.16.410.

49. Ohnami Y, Ikenaga K, Okamoto E, Kikuchi M. The effect of laser acupuncture on the uterine involution in postpartum dairy cows. Tohoku J Vet Clin ; 19(1) : 25-9. doi: 10.4190/ jjvc1990.19.25.

50. Choi I, Kim B, Choi Y. The analgesic effect of laser acupuncture. In: The Commemorative collection of theses in honour of the sixtieth of Dr. Cho Young-sik. Collection of theses. Seoul:Kyung Hee Press. 1981 : 1051-60.

51. Ko K, Kang S. Study on laser acupuncture. Journal of east and west medicines 1986; 11(1) : 77-92.

52. Lee J, Jong S. Livestock disease treatments using laser acupuncture. Korean swine journal $1995 ; 17(1)$ : 77-80.

53. Kim Y. Physical therapy in Korean medicine. Seoul: Hyunmoon Co. 1999: 316-9.

54. Lee H. Physical therapy in Korean medicine. Seoul: Daihakseorim. 2004: 182-3.
55. The Society of Korean Medicine Rehabilitation. Korean rehabilitation medicine. 4th ed. Seoul:Koonja Publisher. 2015 : 394-6.

56. The society of meridian and acupuncture. Practice of acupuncture, a guidebook for college students. 7th ed. Seoul: Jongryonamu Publisher 2015; 122-6.

57. Chester AN, Martellucci S, Scheggi AM. Laser Systems for Photobiology and Photomedicine. NATO ASI Series B. New York:Physics Plenum Press. 1991 : 252 : 115-28.

58. Friedemann T, Shen X, Bereiter-Hahn J, Schwarz W. Regulation of the cardiovascular function by $\mathrm{CO}_{2}$ laser stimulation in anesthetized rats. Lasers Med Sci. 2012 ; 27(2) : 469-77. doi: 10. 1007/s10103-011-0973-3.

59. Zand N. Non-thermal, non-ablative $\mathrm{CO}_{2}$ laser therapy (NACLT): a new approach to relieve pain in some painful oral diseases: In:Dumitras DC. $\mathrm{CO}_{2}$ Laser-optimisation and application. Croatia: InTech; 2012:387-414. doi: 10.5772/37828. 